In collaboration with the University Extension Commit. tee of the Technical University of Denmark a series of lectures entitled "Atomic Energy-its Implications and Utilization" have been given in Hjørring and Elsinore. The Library issued 24,014 items on loan during the year, and 2,045 books, periodicals and reports were borrowed from other libraries. On March 31, 1962, the total holding of the Library consisted of 95,000 bibliographical units, of which 30,000 were on microcards.

S. Weintroub

\title{
RADIATION HAZARDS IN PERSPECTIVE
}

$\mathrm{T}$ HE Expert Committee on Radiation of the World Health Organization consists of a group of international experts under the chairmanship of Lord Adrian. The Committee, together with representatives of several other organizations, met in Geneva during October 24-30, 1961 , to discuss the relative somatic and genetic effects of ionizing radiation and of other agents and substances in our environment which have toxic, carcinogenic or mutagenic properties. The report of that meeting has now been published *.

Prominence has been given in recent years to the hazards of ionizing radiation and intensive studies have been made of radiation injuries and elaborate protection measures devised. Emphasis, however, should also be given to the beneficial aspects of many procedures involving radiation exposure, for it is well known that the benefits of the appropriate medical use of radiation in diagnosis and therapy far outweigh the hazards. With adequate protective measures, radioactive materials and nuclear energy can be peacefully and usefully applied in industrial and technological fields.

The report warns that preoceupation with the problems of radiation hazards may obscure the fact that there are many other toxic agents in the environment, some very widespread, which could prove a greater menace to public health. Man-made hazards to health must be reviewed against the background of known or unknown causes of disease, co-extensive with the whole field of medicine. In less-developed areas, man-made hazards account for only a small proportion of illness, but in highly developed areas they are responsible for a significant fraction of illness and death. The statistics given in the report show that in many countries accidents rank third as a cause of death and constitute the leading cause of death in the younger and more productive age groups. Most of the reported injuries caused by chemical toxins have occurred in industry, but increasing attention is being directed to the dangers of air pollution, pesticide residues in food, and food additives. A wide variety of chemical compounds are now known to be carcinogenic and others have been shown experimentally to be capable of genetic changes.

Turning to self-imposed hazards, the report states that it appears quite obvious that cigarette smoking or something closely associated with it is largely responsible for the high incidence of bronchiogenic carcinoma in certain

* World Health Organization. Technical Report Series. No. 248. Radiation Hazards in Perspective: Third Report of the Expert Committee on Radiation. Pp.
H.M.S.O., 1962.)
2 Swiss franes; $38.6 d . ;$
0.60 dollars. countries. Some anomalies in the geographical distribution of lung cancer strongly suggest that other agents are partly responsible. The most substantial evidence appears to be the higher incidence in urban than in rural smokers. The medical use of radiation for therapy of non-malignant conditions and of diagnosis, where, in the early days of radiological practice, excessive doses may have been given, has occasionally been shown to lead to malignant disease, and there is still need for care and research in this field. The genetic effects of radiation, chemicals and temperature are discussed in some detail. The total incidenoe of hereditary diseases and defects in man may be estimated at about 6 per cent of all live births. The discovery recently that a surprisingly high frequency of defects in man are associated with anomalies of chromosome number or structural aberrations of the chromosomes suggest, since such types of abnormalities can be produced by radiation, that radiation hazard is more extensive than suspected before. The role of mutation in maintaining the hereditary burden in man is still under debate and an answer is likely to be arrived at very slowly. Mutations in all animals and plants occur naturally, and although the causes of these spontaneous mutations are not well understood, it is estimated that only a small fraction could be due to the natural back. ground radiation to which all living things are exposed. There is no a priori reason for believing that ionizing radiation is the only, or even the main, environmental factor in the production of mutations. Some hundreds of chemical agents are known to be mutagenic, but none has been investigated in such detail as radiation. The report calls for more research to assess the genetic hazards of mutagenic chemicals and temperature.

In their concluding remarks, the Committee recommends that studies be undertaken to establish criteria for safe exposure-levels to toxic agents, both for individuals (as in the case of occupational exposure) and for populations (as in the case of pollution of water, food and air). The suggestions that certain chemical agents may have deleterious somatic and genetic effects similar to those produced by ionizing radiations should be investigated, and the international standards of statistical reporting of effects, damage, disability and death because of toxic materials should be improved. In addition, epidemiological and genetic studies of the effects of toxic materials should be made and intensive research stimulated on the mechanism of action of these materiais including their carcinogenic and genetic effects.

\section{TOBERMORITE GEL IN CONCRETE}

\begin{abstract}
$\mathrm{T}$ OBERMORITE is now known to be the chief cementing compound in hardened Portland cement and its structure largely determines the properties of concrete. When Portland cement is mixed with a limited amount of water, a plastic, mud-like material called 'cement paste' rosults; it sets in a matter of hours, becoming reasonably firm, then continues to harden for a period of months, if not years. The hardened paste is the matrix into which the fine and coarse crushed rock or natural sand and gravel enter, thus forming the artificial rock called concrete. Stephen Brunauer, of the Portland Cement
\end{abstract}

Association, Illinois, discussed the role of tobermorite gel in concrete at a lecture to the Institute of Civil Engineers in London in July 1962 and a transeript appeared in Structural Concrete (1, 7; January/February, 1963); this has since been reprinted for the Cement and Concrete Association, London.

Brunauer's thesis is briefly as follows. Portland cement is a complex mixture of oight or more compounds of which the two most important are known to be tricalcium silicate $\left(\mathrm{Ca}_{3} \mathrm{SiO}_{5}\right)$ and $\beta$-dicalcium silicate $\left(\beta-\mathrm{Ca}_{2} \mathrm{SiO}_{4}\right)$, these two silicates constituting about 75 per cent of an 